\title{
EMPOWERMENT OF WOMEN AND POVERTY REDUCTION IN DEVELOPING COUNTRIES
}

\author{
Natalia Bueno, \\ Energy Industries Council
}

\author{
Dr. Roger Morefield, \\ University of Saint Thomas
}

\begin{abstract}
The purpose of this paper is to analyze the relationship between women's empowerment and poverty, topics that are part of the UN Millennium Development Goals. An analysis of a sample of 36 low and middle income countries divided equally among 6 different regions shows that education and health are important factors in determining the level of development. Findings suggest that the implementation of certain types of programs empower women and gradually alleviate poverty.

Keywords: Women Empowerment, Poverty Reduction, Developing Countries.
\end{abstract}

\section{INTRODUCTION}

In 1995, then-U.S. First Lady Hillary Rodham Clinton stated during the $4^{\text {th }}$ United Nations Conference on Women in China: "What we are learning around the world is that if women are healthy and educated, their families will flourish. If women are free from violence, their families will flourish. If women have a chance to work and earn as full and equal partners in society, their families will flourish. And when families flourish, communities and nations do as well" (Valenzano III and Braden 2012, 274) In other words, Mrs. Clinton explained that when women are empowered they will improve their living conditions and this will be reflected in their families and the economy thus helping their community and country. This paper supports Clinton's assertions that there is a need to empower women in order to alleviate poverty. The hypothesis herein is that empowerment of women does lead to poverty alleviation in developing countries. Dorius (2010), Ezeh et al. (2012), and Ahmed (2010) have shown that programs focused on microcredit loans and furthering education, health and sanitation, help women progress in their communities and allow them to gain 
decision-making power and self-confidence as well as higher levels of income and more stable wages.

A definition of empowerment is needed at this point. "Empowerment denotes a process of acquiring, providing, bestowing the resources and the means or enabling the access to and control over such means and resources. This implies that the individual has the potential to acquire her own initiative or that another party could make it possible for her to have power (Medel-Anonuevo 1995, 25). Put simply, women's empowerment refers to the process by which women are given resources or access to them in order to gain self-confidence and social standing which could lead to them earning higher wages, owning land or a small business, investing in their children's education, and reducing their risk of death in childbirth or from sexually transmitted infections. In fact, research conducted by the International Center for Research on Women (ICRW) illustrates that when women attain high levels of education they are more inclined to make improvements in their lives and at a local level. This is why ICRW and other international development organizations lobby governments in developing countries to provide greater support for more education for girls and women (ICRW 2005).

In 2000, many political leaders and organizational representatives throughout the world came together under the forum of the United Nations to set out a plan of action to improve upon 8 target areas which became known as the Millennium Development Goals (MDGs). These goals had the core purpose of reducing poverty and improving the quality of life for the poor by 2015 . Understanding that about half of the world's population is female and about $70 \%$ of them are in poverty, this article attempts to provide an explanation of possible approaches for the eradication of extreme poverty \& hunger, and to emphasize the importance of promoting gender equality and empowering women. It is necessary to target women as a gateway to poverty eradication because women are normally in charge of educating the children. This leads to the idea that if women obtain higher levels of schooling they can provide their children with better living conditions because they have more power, more income and a better understanding of the importance of a good education and better health. According to the Clinton Global Initiative, "a mother with a few years of formal education is considerably more likely to send her children to school, breaking the intergenerational chain of poverty. In many countries each additional year of formal education completed by a mother translates into her children remaining in school for up to an additional one-half year" (Clinton Global Initiative, 2012). Likewise, the Population Reference Bureau found in a (...) study of 19 developing countries that, "a country's long-term 
economic growth increases by 3.7 percent for every year the adult population's average level of schooling rises." (PRB 2003) These numbers illustrate the impact that education and women's empowerment alike can have on a country's development and future economic prosperity.

Given the information presented above, this paper argues for the need to empower women in order to alleviate poverty in developing countries. Humanitarian non-governmental organizations (NGOs) CARE and the Girl Effect provide two arguments that reinforce the notion of a need to empower women by showing that making an investment in the women of one community can result in intergenerational benefits because those women will teach their children how to escape poverty and in turn those children would teach their descendants this becomes a virtuous cycle supporting poverty elimination and economic development. CARE found that "a woman's earnings will be 10-20\% higher for every year of school completed" (Care 2011). The Girl Effect, a project started by Nike to empower girls and young women, finds that "when women and girls earn income, they reinvest 90 percent of it into their families, as compared to only 30 to 40 percent for a man" (The Girl Effect 2012). These two statements support the hypothesis that education improves women's economic standing and they will seek to further their family's economic conditions as a result.

It is argued herein that empowering women in developing countries is conducive to poverty reduction. Furthermore, it intends to bring awareness to this idea. Investing in women allows for the development of humanity on a global scale. Although many people think that they are relatively unaffected by this issue, women in many parts of the world strive for this empowerment daily while others in developed countries take these rights for granted.

This paper is organized as follows. Following this introduction, section 2 is a literature survey and review of past research that has been done in this area and is of relevance to the main objective of this study. Section 3 discusses the methodology implemented to test the hypothesis and provides specifics as to how the data were collected for the 30 developing countries. Section 4 analyzes the findings using linear regression and provides quantitative information in support of the hypothesis. Section 5 provides a summary and conclusions, along with some policy recommendations for the international development community.

\section{LITERATURE REVIEW}

There exists an extensive amount of literature relative to women's empowerment. The lingering problem of gender inequality creates a breach between men and women and creates obstacles for women to 
prosper in their community. These obstacles are the reason women's empowerment is needed because it has been shown through many studies that implementing programs that set out to empower women reduce the gender gap and give women a better social and economic standing in their communities. Dorius (2010) demonstrated the trends in worldwide gender inequality by incorporating 2008 UN data which was used to track the progress in reaching the Millennium Development Goals. Ezeh et al (2012) provides a more specific example which analyze the gender issues in the National Fadama 1 Development Project in the Abia State of Nigeria.

Dorius (2010) focused on studying whether men and women are uniting or deviating in regards to educational achievements, longevity, economic activity and political participation. By using the GINI index, Dorius (2010) found that 2.1 billion adults in 193 countries, split almost evenly among men and women, only about $45 \%$ of the women are literate. Likewise, Ezeh et al (2012) used the GINI index as a variable to find that men had an index of about 0.23 while women had an index of about 0.35 , demonstrating that women have lower income levels than men and higher levels of poverty. Dorius (2010) concluded that there are still significant differences among men and women in terms of economic and political activity. Ezeh et al (2012) found that men had larger farms than women and consequently have higher incomes from agriculture. Dorius (2010) goes further than Ezeh et al (2012) by showing that uneven growth of population has slowed the increase in gender equality, and that there is no specific region in the world where gender inequality is rising. In addition, gender inequality in all religious traditions is declining. Overall, both articles provide a framework in support of the need to study the relationship between empowering women and alleviating poverty.

In addition to the above, the scholarly literature microcredit or microfinance programs illustrates the impact of these programs on women's lives. Salt (2010) set out to describe the relationship between the

Inquipy 2016/2 health of American women that live in the U.S. Pacific Northwest and their businesses and examined their participation in a microcredit program in the United States. Its counterpart in a developing country would be Islam et al. (2008) which explained the Rangpur Dinajpur Rural Service credit in Bangladesh and its effect on the women that requested these loans. In another example, Shetty (2010) compared two microcredit programs conducted in the same slum in India, one by Working Women's Forum and the other by Guild of Service. Shetty focused on the effect of these microcredit programs on empowering women and reducing poverty. A study by Sindhe et al (2013), also conducted in 
India, surveyed the effects of globalization and trade liberalization on the disparity between men and women. They found these effects to be generally negative, suggesting microfinance as a possible mitigating factor. Although all these studies discuss microcredit or microfinance programs, Shetty (2010) is the only one that specifically treated the relationship between microcredit programs and women empowerment. While Salt (2010) and Islam et al (2008) focused on the impact of microcredit loans on the lives of the women that use them, Sindhe et al (2013) see microfinance as a partial solution to the gender disparity in India, enhancing women's empowerment and reducing poverty.

Salt (2010) explained that the majority of those who participate in microcredit programs are women and that they encounter certain barriers such as prolonged disbursement periods or insufficient funds to start their business. This increases their likelihood of defaulting on their loan, or of increasing their debt, or of reducing their creditworthiness. On the other hand, Sindhe et al (2013) argued that microfinance programs would allow women to gain a sense of economic self-reliance because they can avoid discrimination by lenders and gain credit and saving opportunities through these programs. This in turn this would create an upward spiral in which they gradually increase their income and their contribution to their family, possibly elevating their standing within their household. Numerically, Shetty (2010) found that $52 \%$ of plan recipients in Chennai, India had reported an increase in their level of income due to their access to loans and small grants. In addition, Islam et al (2008) illustrated that the percentage living below the poverty line was lower than the national average which means that there was a reduction of poverty amongst the study group because they joined Rangpur Dinajpur Rural Service. These data show that the participation of women in this program improved their economic standing and sustainability just as Sindhe et al. (2013) and Shetty (2010) had argued above.

Salt (2010) concluded that women found the microcredit program helpful and recommended it to others. In addition, he found that the initial economic level of these women constrained their access to healthcare so if they were to fall ill they could lose their business. Therefore, Salt recommended that these microcredit programs should include educational programs that enhance the health of the participating women and their families. In her findings, Shetty (2010) concluded that the two microcredit programs had a small impact on poverty reduction on the basis of credit alone but that they allowed women to access low-interest loans that they otherwise wouldn't have been able to access. On the contrary, Islam et al. (2008) established that in Bangladesh women 
in the RDRS program tried to improve their economic conditions by using credit in order to diversify their sources of income, which led to a notable improvement in their living standard and an improvement in their livelihood. As with Islam et al. (2008), Sindhe et al. (2013) stated that their participation in economic activity allows women to obtain new skills and further interact in their society, which would improve their social standing. But Sindhe clarified that an important element in this solution is the availability of microfinance as the easiest way for women to expand their economic participation. As mentioned earlier, Salt (2010) argued that the obstacles that women face when participating in microcredit programs do not allow them to fully benefit from the prosperity and improvements that can result from these microcredit loans. Sindhe et al. (2013) found that microcredit programs are crucial for women's interaction with the economy and with their society.

Regarding health and its connection to women's empowerment, Ahmed (2010) looked at how the 3Es (education, empowerment, and economic status) affect the use of maternal health services. In a more detailed study, Do \& Kurimoto (2012) analyzed the use of contraceptive methods and women's empowerment in four African countries. Similar to Ahmed (2010) but with a focus on HIV, Krishnan (2008) studied the social structure, based on poverty and gender disparity, that causes women to be more prone to HIV infection and proposed alterations to this structure that would decrease the likelihood of women becoming HIV positive.

In making his case, Ahmed (2010) mentioned an idea presented by Thaddeus and Maine that explains three factors that could possibly cause higher rates of maternal mortality. Those factors are postponement of getting needed medical attention, arriving late at a healthcare facility, and delayed care upon arrival (these are also known as the 3Ds). Ahmed (2010) argued as a result that the 3Ds are exacerbated if a woman has low levels of the 3Es. In order to properly study the connection between women's empowerment and contraceptive use, Do \& Kurimoto (2012) explained the Malhotra and Schuler method which measures women empowerment throughout 6 fields ("economic, sociocultural, familial/ interpersonal, legal, political and psychological") and multiple social levels. Do \& Kurimoto (2012) provided a general framework under which the 3Ds mentioned by Ahmed (2010) are a deficiency in women empowerment in sociocultural aspects, understanding that both authors intended to study the connection between women's empowerment and access to health care services. Similarly, but with a sole focus on HIV, Krishnan (2008) identified four main issues within the social structure. These are: the limited access to information and medical attention for 
HIV and other STIs, reduced levels of formal education and other forms of skill development, increased domestic violence amongst couples, and lastly the negative outcomes of migration due to the lack of economic wealth.

Ahmed (2010) concluded that women that have deficiencies in the 3 Es are less likely to seek maternal healthcare. He clarified that out of all the 3Es women's empowerment proved to be the least influential in incentivizing women to seek prenatal care, contraceptives, or proper birthing attendance. However, Ahmed (2010) still believed that by improving a woman's socio-economic standing through education, increased economic opportunities and empowerment, she is more prone to use maternal health services which would in turn reduce health disparities. Correspondingly, Do \& Kurimoto (2012) concluded that programs aimed at improving the use of contraceptive methods must incorporate multiple approaches such as increased economic independence, promoting dialogue between couples on family planning, and improving women's decisive power in terms of sexual activity. Like Ahmed (2010) and Do \& Kurimoto (2012), Krishnan (2008) concluded that there are many difficulties in altering this social structure but argued that by reducing migration, expanding access to prevention information on HIV and other STIs, increasing women's employment opportunities and level of educational attainment, and involving their communities in order to reduce the gender gap and alleviate poverty, pathways to HIV risk can be modified. It is within this framework that the authors reach the general conclusion that women's empowerment is a pathway for women to escape poverty, and reduce health disparities in all aspects, whether it is the use of maternal health services, use of contraceptives, or likelihood of contracting HIV.

In terms of women's empowerment and education, Yousefy \& Baratali (2011) discussed whether or not a woman's education level influences her likelihood of having an active working life, as well as her employment status. In addition, Awan et al. (2011) examined the relationship between poverty, level of education, and experience and gender in order to understand how these three factors affect poverty. They believe that there is an inverse relationship between poverty and education levels. On a regional and local level, Jayaweera (1997) explained the link between education and three areas of empowerment (economic, social, and political) in Asia. Meanwhile, Murphy-Graham (2008) set out to clarify the connection between empowering women and education in Honduras and argued that in order for education to empower women it must increase their self-confidence, expand their pool of knowledge, and makes them conscious of the need for further gender 
equality. Lastly, Malik (2011) examined the influence that a higher education degree has on women's empowerment in Pakistan.

Throughout his study, Murphy-Graham (2008) found that in many Honduran villages, women work more hours a day than men mainly because these villages have an agriculture-based economy and men are only responsible for harvesting the crops. Murphy-Graham explained that most of these women only earn income from the crops that are sold to the surrounding urban areas and depend largely on their husbands for financial support, which the men earn by fishing. Yousefy \& Baratali (2011) clarify that although the participation of women in educational programs has increased, it does not necessarily mean that women will receive employment upon graduation, but the improvement as a result of more education will be reflected in family life. Similarly, Malik (2011) has found that by participating in higher education programs women are able to break through this social layering of male predominance and that women declared themselves to have a better standing in their family and community as well as greater economic autonomy. In terms of poverty reduction, Awan et al. (2011) found for the 1998-1999 data, that as the level of education increases the likelihood of becoming poor decreasing by showing that the middle (lowest level) decreases these odds by about $58 \%$ while the professional degree (highest level) allows for a reduction of $99.4 \%$. Despite the findings of other authors, Jayaweera (1997) found that the relationship between educational attainment and a woman's economic well-being is almost non-existent, and schools that include gender roles in their educational processes produce women with a negative self-perception which is an obstacle to further empowerment. So not all education programs empower women.

Yousefy \& Baratali (2011) concluded that women with higher degrees enjoy more job promotions and a better work life, as well as better job positions. They also found that because women know of the disparities in their society and the preference for men in the labor market, they are not incentivized to participate in furthering their education.

Inquipy 2016/2 But the authors believe that by obtaining a higher education women can increase their probability of finding a good job and earning a higher salary. In support of this idea, Murphy-Graham (2008) concluded that education must enhance a women's self-confidence, further her knowledge and increase her awareness of the need to foster gender equality. In addition, Awan et al. (2011) emphasized in their concluding arguments that women have greater difficulty escaping poverty because of the discrepancies in employment opportunities and their access to education. These papers support the idea that awareness of gender inequality and pursuing education can lead women to prosper in their society. 
It is precisely this explanation that led Malik (2011) to recommend that educational programs include strategies to reduce the gender disparities at all levels and focus on promoting furthering women's educational opportunities into higher level education. Contrary to these findings, Jayaweera (1997) concluded that education cannot counteract economic and social obstacles that cause women to live in poverty, nor has it been able to reduce the impact of gender differentiation in the social realm which causes greater disparities between men and women.

In regards to women's empowerment and development, Campbell (2010) explained how global governance plays a role in the work on which women embark in order to reduce disparities among genders, and how this relates to international goals of reforming development aid, specifically in Kyrgyzstan. On a more micro level, Campbell (2010) and Varghese (2011) evaluate women's empowerment in Oman by examining the ability of women to make household choices, economic decisions, and assert influence \& interest in propagating women's empowerment. Booysen-Wolthers \& Botes (2011) studied whether or not the decline in the development of women from the years of 1996 to 2001 was widespread throughout the nine provinces of South Africa as well as the trends in development in these areas. Kadam (2013) set out to discuss different aspects of women's empowerment with a focus on India. Mutongu (2012) studied the underlying factors that inhibit the active participation of women in their community based on the causality between development and empowerment. That is, it is necessary to empower individuals in order for women to gain access to the opportunities around them by allowing them and their society to progress economically and become more just. In other words, it would allow them to develop. Banerjee \& Duflo (2008) set out to understand why governments and other development institutions believe that making the poor responsible for their future is more effective, and to discover whether or not the poor have the disposition to take action in order to change their situation.

Campbell (2010) argued that while women have the power to enact rules, these women also work to conduct women's empowerment programs that contribute to their effectiveness. However, in Oman Varghese (2011) pinpointed the discrepancies between the noticeable improvements of women's standing in Omani society as opposed to the results from the secondary data which show that this process had been much lengthier and that Omani women are still hesitant to take a more active role in their community. While Booysen-Wolthers \& Botes (2011) found that in South Africa the women that inhabited the 3 provinces with the largest gender gap became more affected over time 
(greater weakening of the gender gap) than the 3 provinces with the smallest gender gap. The authors then concluded that women who were initially disadvantaged became worse off because they were losing ground to the men in these 3 provinces. Kadam (2013) discussed economic, political, judicial and social empowerment. He explained that these forms of empowerment allow women to have a better standing in their community and greater opportunities for development. Mutongu (2012) stated that the level of education, political factors, leadership experience, sociocultural problems, familial obligations and religious beliefs all influence the level of participation that a woman has in the community, namely in community-based organizations (CBOs). Banerjee \& Duflo (2008) found that a significant portion of the poor population in low-income countries act as entrepreneurs by investing, seeking capital and claiming all earnings. As for education, although $93 \%$ of 6 to 14 -year-olds claim that they go to school, only $43 \%$ of fifth graders can do simple math, and even more alarmingly, only $60 \%$ can read at second grade level.

Campbell (2010) concluded that "aid effectiveness works as a ruling frame that directs people to interpret their lives and experiences in particular ways and within which they learn to take action appropriate to it." Varghese (2011) determined that according to the Women's Empowerment Index, women in Oman are empowered but lack the interest in home life which reduces their empowerment; and that women's focus should be to confront patriarchal powers which are what generates gender inequality. Booysen-Wolthers \& Botes (2011) decided, based on the analysis of their data, that there was an overall decline (intra-gender and inter-gender) in women's development from 1996 to 2001 in the nine South African provinces studied. Kadam (2013) concluded that although India has laws that aim to empower women, there is still a need to create further gender equality in modern India. Mutongu (2012) concluded that education is a key tool for improving women's participation because it provides them with a skill set and enhanced self-confidence concluded that governments, institutions, and society as a whole should consider that we cannot assume that the poor will solve their problem mainly because there are external factors that affect their ability to effectively move out of poverty, and we don't comprehend what moves them to seek change. 


\section{METHODOLOGY}

In order to test the relationship between ' $x$ ' and ' $y$ ', a linear regression analysis was performed. In particular, two equations were used to test the extent to which empowering women leads to poverty reduction in developing countries.

Thirty-six countries were selected as the sample for the linear regression analysis. The countries are all developing countries, classified by the World Bank as low-income, lower-middle income, and upper-middle income countries. In addition, six countries were selected for each of the six developing regions across the globe. ${ }^{1}$ These particular countries were chosen in order to study the impact of women's empowerment on reducing poverty in developing countries with slightly different degrees of development and with different political and social structures.

Equation 1 measures the relationship between poverty in developing countries and the impact on women's empowerment. Women's empowerment is quantified using a series of independent variables which include the GINI Index, female population in the country, GDP per Capita, Human Development Index, Inequality-adjusted Human Development Index, gender inequality, poverty gap, Multidimensional Poverty Index, female primary completion rate (\% of relevant age group), youth female literacy rate and ratio of female to male primary/secondary/tertiary educational enrollment, female headed households, prevalence of HIV, fertility rate (total births per woman), contraceptive use and maternal mortality rate. In addition, poverty (the dependent variable) is defined as the number of people living on less than $\$ 2$ a day.

$$
Y_{1}=\Gamma_{1} X_{1}+\Gamma_{2} X_{2}+\Gamma_{3} X_{3}+\Gamma_{4} X_{4}+\Gamma_{5} X_{5}
$$

It is reasonable to expect that a society in which a significant amount of people living on less than $\$ 2$ a day will have a low gross domestic product in terms of purchasing power parity. In addition, developing countries that are more impoverished will be more unequal in terms of the GINI Index and a have more negative relationship with the Human Development Index and the Inequality-adjusted Human Development Index. Similarly, it is anticipated that developing countries that have land, Indonesia, Malaysia and Cambodia. In Europe and Central Asia, Azerbaijan, Kazakhstan, Romania, Ukraine, Turkey and Bulgaria were selected. Latin America and the Caribbean region include the Dominican Republic, Argentina, Bolivia, Honduras, Suriname and Jamaica. For North Africa and the Middle East, Egypt, Jordan, Algeria, Tunisia, Yemen and Morocco were selected. The South Asian countries are India, Pakistan, Bangladesh, Sri Lanka, Nepal and Bhutan. Lastly, Sub-Saharan Africa is represented by Nigeria, Ghana, Kenya, Cameroon, Uganda and Liberia. 
more people living on less than $\$ 2$ a day will also have a large poverty gap and a more unequal society in terms of gender. The female primary school completion rate ( $\%$ of relevant age group), youth female literacy rate, and ratio of female to male primary/secondary/tertiary enrollment could be expected to increase as poverty is reduced throughout these developing countries. It is also reasonable to assume that as communities experience less poverty the prevalence of HIV infection will diminish, fertility rates (total births per woman) decrease, there is more contraceptive use, and the maternal mortality rate is significantly reduced. Another reasonable assumption is that large female populations can be conducive to more impoverished communities in these developing countries due to the lack of women's empowerment. One could expect the relationship between the Multidimensional Poverty Index and poverty measured by the number of people living on less than $\$ 2$ a day to reflect that as poverty rises people are increasingly deprived of proper living conditions, education, and health. Finally, it is expected that the smaller the various indicators of poverty, the greater the number of women that are head of household.

The second equation measures the relationship between development and women's empowerment. In this case, the dependent variable is development and is measured by using the Gross Domestic Product (GDP) per capita in purchasing power parity dollars. The independent variables used to determine women's empowerment are the GINI Index, female population in the country, people living on less than $\$ 2$ a day, the Human Development Index, the Inequality-adjusted Human Development Index, gender inequality, the Multidimensional Poverty Index, poverty gap, female primary school completion rate (\% of relevant age group), youth female literacy rate and ratio of female to male primary/ secondary/tertiary enrollment, female headed households, prevalence of HIV, fertility rate (total births per woman), contraceptive use, and maternal mortality rate. The second equation that is used for the second part of the analysis is shown below:

$$
Y_{2}=\Gamma_{1} X_{1}+\Gamma_{2} X_{2}+\Gamma_{3} X_{3}+\Gamma_{4} X_{4}+\Gamma_{5} X_{5}
$$

It can be expected that development (measured by GDP per capita) should improve as the use of contraceptives increases, and the prevalence of HIV, fertility rates and maternal mortality rates would decrease. In terms of the education variables, the dependent variable should increase as the female primary school completion rate, youth female literacy rate, and ratio of female to male primary/secondary/tertiary enrollment reach higher levels. Since the purpose of this study is 
to explain the role of women's empowerment in poverty alleviation, female headed households as a measure of women's empowerment could be expected to be directly related to GDP per capita. Based on the idea that there is a lack of women's empowerment, it is safe to assume that the more women there are in a society, the lower the GDP per capita.

It is assumed herein that a decrease in gender inequality and the GINI index (as it gets closer to 0, income distribution becomes more equal) is linked to higher levels of GDP per capita. Contrariwise, a greater Inequality-adjusted Human Development Index and Human Development Index should be related to higher levels of GDP per capita. In terms of poverty, the greater the number of people living on less than \$2 a day, the larger the poverty gap and the lower the GDP per capita. The reason for the expected relationship between GDP per capita (dependent variable) and the Multidimensional Poverty Index (independent variable) is that as more people live in multidimensional poverty (at least $33 \%$ of each of the 3 sectors show severe deprivation), GDP per capita would be lower.

\section{DATA AND RESULTS}

In order to analyze the relationship between women's empowerment and poverty reduction in developing countries, a linear regression analysis with data for 36 developing countries was conducted. The data are divided amongst six different regions, as noted above. The first dependent variable in this analysis is poverty which is measured by the number of people living on less than two dollars a day in each of the selected countries. It is expected that in general the worse off women are across the board, the more likely they are to be living on less than two dollars a day.

Table 1 shows estimation results of the first equation. The initial hypothesis of the relationship between poverty and measures of maternal health is supported by the data. Note that the data were transformed into natural logarithms, which means that the estimated coefficients are elasticity coefficients. Initially, it was hypothesized that higher levels of poverty would be conducive to a greater prevalence of HIV, higher numbers of births per woman, less use of contraceptive methods and a higher maternal mortality rate.

The data indicate that a $10 \%$ increase in total prevalence of HIV for people between the ages of 15 and 49 is associated with a $3.98 \%$ decrease in the percentage of people living on less than two dollars a day. Although this outcome is statistically significant at a $95 \%$ level of confidence it refutes the initial hypothesis. The conventional wisdom 
would be that a country with higher levels of poverty would also have more cases of HIV, but the analysis indicates the opposite. For the next variable, the expectation is that women would have more children in countries with higher levels of poverty. Table 1 column 1 shows that for a $10 \%$ increase in total fertility rates (more births per woman), is associated with an $18.86 \%$ increase in the percentage of people living on less than two dollars a day. Thus, these results support the initial assumption with a $95 \%$ level of confidence.

Table 1: Relationship between Maternal Health and People Living on Less than $\$ 2 /$ day $\left(Y_{1}\right)$

\begin{tabular}{|c|c|c|}
\hline$x$ & 1 & 2 \\
\hline Total Prevalence of HIV (ages 15-49) & $\begin{array}{r}-0.398^{*} \\
(0.175)\end{array}$ & - \\
\hline Total Fertility Rates (Births/Women) & $\begin{array}{l}1.868^{*} \\
(0.960)\end{array}$ & $\begin{array}{r}1.808^{* *} \\
(0.949)\end{array}$ \\
\hline Contraceptive Use (ages 15-49) & $\begin{array}{l}1.141^{* *} \\
(0.696)\end{array}$ & $\begin{array}{c}1.171 \\
(0.723)\end{array}$ \\
\hline Maternal Mortality Ratio (per 100,000) & $\begin{array}{l}1.174^{*} \\
(0.321)\end{array}$ & $\begin{array}{l}0.900^{*} \\
(0.311)\end{array}$ \\
\hline $\begin{array}{lll}{ }^{*} \text { Significant at } 5 \% & n_{1}=35 & n_{2}=36 \\
{ }^{* *} \text { Significant at } 10 \% & \text { adjusted } & R_{1}^{2}=0.5213\end{array}$ & & \\
\hline
\end{tabular}

In addition, it was found that a $10 \%$ increase in the use of contraceptive methods in people between the ages of 15 and 49 is associated with an $11.41 \%$ increase in the percentage of people living on less than $\$ 2$ a day. This finding indicates that, at a $90 \%$ level of confidence, greater use of contraceptive methods would lead to more people living on less than two dollars a day. A possible explanation for this result is that the users of contraceptive methods are not implementing the method of choice correctly therefore it is ineffective and does not truly affect poverty. Or, there may be other factors not captured in this model that are so strong as to cancel out the expected results. The final independent variable in the first linear regression analysis is the maternal mortality rate. Results suggest that a $10 \%$ increase in the maternal

Inquipy 2016/2 mortality rates (more deaths of women per 100,000 births) is associated with an $11.74 \%$ increase in the percentage of people living on less than $\$ 2$ a day, which is consistent with the initial hypothesis. Hence, societies that experience high maternal mortality rates are more likely to have a greater number of people living in poverty.

A second specification of the variable for maternal health, except for the prevalence of HIV, further confirmed the finding explained above. In this regression, a $10 \%$ increase in total fertility rates (more births per women) is associated with an $18.08 \%$ increase in the percentage of people living on less than $\$ 2$ a day. This further supports the idea that women have more children when they live in poverty. In this regres- 
sion, the results for contraceptive use are not statistically significant. However, they confirm the conclusion drawn above by showing that a $10 \%$ increase in the use of contraceptive methods in people between the ages of 15 and 49 is associated with an $11.71 \%$ increase in the percentage of people living on less than $\$ 2$ a day. Lastly, the data once again support the idea that a $10 \%$ increase in the maternal mortality rate (more deaths of women per 100,000 births) is associated with a $9.00 \%$ increase in the percentage of people living on less than $\$ 2$ a day, at a $95 \%$ level of confidence.

The next set of variables discussed herein is measures of development. Table 2 displays the relationships between people living on less than two dollars a day and the GINI index, the Inequality-adjusted $\mathrm{Hu}-$ man Development Index, and the Human Development Index.

Table 2: Relationship between Development and People Living on Less than $\$ 2 /$ day $\left(Y_{1}\right)$

\begin{tabular}{|c|c|c|}
\hline$x$ & 3 & 4 \\
\hline GINI Index & $\begin{array}{c}0.423 \\
(1.058)\end{array}$ & $\begin{array}{c}1.542 \\
(1.015)\end{array}$ \\
\hline Human Development Index & $\begin{array}{l}-2.116 \\
(2.395)\end{array}$ & $\begin{array}{l}-5.392^{*} \\
(0.9501)\end{array}$ \\
\hline Inequality-adjusted HDI 2011 & $\begin{array}{c}-3.265^{* *} \\
(1.890)\end{array}$ & - \\
\hline $\begin{array}{lll}{ }^{*} \text { Significant at } 5 \% & n_{3}=34 \quad n_{4}=36 \\
{ }^{* *} \text { Significant at } 10 \% & \text { adjusted } R_{3}^{2}=0.5994\end{array}$ & adjusted $R_{4}^{2}=0.4914$ & \\
\hline
\end{tabular}

A third specification of this linear regression analysis was conducted to show the relationship between all the variables that measure development in this study and the number of people living on less than two dollars a day. Estimation results show that a $10 \%$ increase in the GINI index (a more unequal society) is associated with a $4.23 \%$ increase in the percentage of people living on less than two dollars a day. This supports the hypothesis that greater levels of inequality are related to higher levels of poverty. However, the estimated coefficient is not statistically significant. The next independent variable is the Human Development Index, which is measured on a scale from zero to one with zero indicating a country with a very low level of human development and a one indicating a country with very high level. The results show that a $10 \%$ increase in the human development index is associated with a $21.16 \%$ decrease in the percentage of people living on less than two dollars a day. In other words, the higher the level of human development in a country, the lower the number of people living on less than two dollars a day. Yet, this result is not statistically significant. The final variable for this part of the regression is the inequality-adjusted 
HDI which uses the same technique to measure social and economic development as the HDI but is adjusted for inequality, which enables this index to quantify the losses of human development that result from inequality. The interpretation of this coefficient is as follows: a $10 \%$ increase in the inequality-adjusted human development index is associated with a $32.65 \%$ decrease in the percentage of people living on less than $\$ 2$ a day. Unlike the first two coefficients, this one is statistically significant at a $90 \%$ level of confidence.

Table 3: Relationship between Poverty and People Living on Less than $\$ 2 /$ day $\left(Y_{1}\right)$

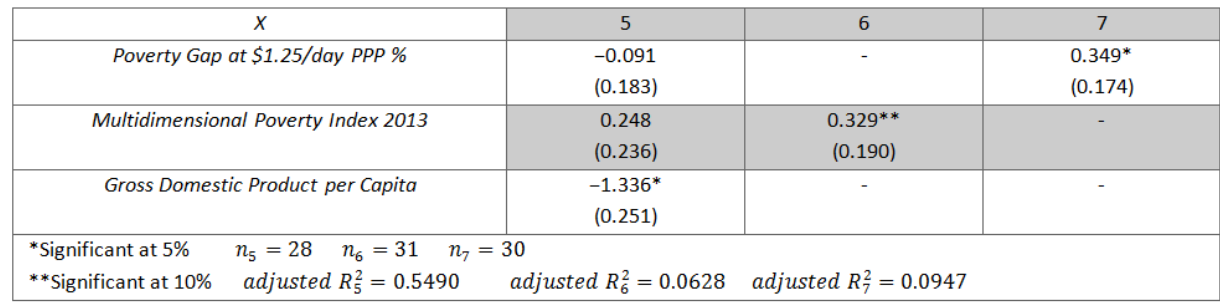

Specification 4 omits the adjusted Human Development Index and although the estimated coefficients are larger in magnitude, the results mimic the ones from the previous specification. The data support the idea that a $10 \%$ increase in the human development index is associated with a $53.92 \%$ decrease in the percentage of people living on less than two dollars a day. It is important to note that in this regression this outcome was statistically significant with a $95 \%$ level of confidence. Therefore, there is a significant relationship between the Human Development Index and the number of people living on less than two dollars a day, with the understanding that societies that have very low levels of social and economic development will have a greater number of people living in poverty.

The independent variables in Table 3 are used as measures of poverty/income and are used to compare the relationship between dif2016/2 ferent measures of poverty/income and the number of people living on less than two dollars a day. In order to properly analyze the first variable in Table 3, it is important to understand the difference between the poverty gap at $\$ 1.25$ a day and the number of people living on less than two dollars a day. The World Bank website explains the poverty gap as the average shortage from the poverty line at $\$ 1.25$ a day in percentage terms and clarifies that this allows measurement of the occurrence and magnitude of poverty. Put simply, it is a more complete measure of the size of the poverty gap as compared to the poverty line at $\$ 1.25$ a day or the average poverty gap divided by the poverty line at $\$ 1.25$ a day. 
The average poverty level is measured by dividing the total poverty gap and the total population. To further clarify, the total poverty gap is in essence the amount of income that is required to bring the people living below the poverty line up to the poverty line at $\$ 1.25$ a day. Table 3 shows three different specifications. The first one suggests that a $10 \%$ increase in the poverty gap is associated with a $0.91 \%$ decrease in the percentage of people living on less than $\$ 2$ a day. In relation to the poverty line there is a greater difference between the sum of the difference between the poverty line and actual income levels of all people living below that line - requires more money to bring everyone who is below that line up to the line. This finding does not support the hypothesis and has no statistical significance.

The following independent variable, the multidimensional poverty index, is a measure of acute poverty that classifies an individual as multidimensionally poor if he/she suffers deprivations in $33.33 \%$ or more of three dimensions (health, standard of living and education). Therefore, the estimated coefficient shows that a $10 \%$ increase in the multidimensional poverty index is associated with a $2.48 \%$ increase in the percentage of people living on less than two dollars a day. So, an increase in the multidimensional poverty index, or the result of the multiplication of the population that is multidimensionally poor and the 'intensity of deprivation,' would indicate a greater number of people living on less than two dollars a day. Nevertheless, this relationship is not statistically significant. Lastly, the data support the initial hypothesis on the relationship between the Gross Domestic Product per capita and the number of people living on less than two dollars a day with a $95 \%$ level of confidence. The estimated coefficient shows that a $10 \%$ increase in the GDP per Capita, higher level of income, is associated with a $13.36 \%$ decrease in the percentage of people living on less than two dollars a day.

The next two specifications show estimated coefficients that are statistically significant at a $90 \%$ level. Estimated coefficients suggest, that a $10 \%$ increase in the multidimensional poverty index is associated with a $3.29 \%$ increase in the percentage of people living on less than two dollars a day. In other words, the greater the number of people that are multidimensionally poor, the greater the number of people living on less than two dollars a day. On the other hand, a 10\% increase in the poverty gap (requires more money to bring everyone who is below that line up to the line) leads to a $3.49 \%$ increase in the percentage of people living on less than two dollars a day. Given these estimates, it can be concluded that a country with a large poverty gap at $\$ 1.25$ a day will have more people living on less than two dollars a day. 
Table 4: Relationship between Gender and People Living on Less than $\$ 2 /$ day $\left(Y_{1}\right)$

\begin{tabular}{|c|c|c|}
\hline$X$ & 8 & 9 \\
\hline Female Population (Thousands) & 0.078 & 0.208 \\
& $(0.173)$ & - \\
\hline Female Headed Households & -0.519 & - \\
\hline & $(0.565)$ & \\
\hline Gender Inequality Index 2012 & $3.941^{*}$ & $(0.998)$ \\
*Significant at 5\% $\quad n_{8}=28 \quad n_{9}=36$ & & \\
**Significant at 10\% & adjusted $R_{8}^{2}=0.3552 \quad$ adjusted $R_{9}^{2}=0.0103$ \\
\end{tabular}

Table 4 shows the results of the analysis that was conducted in order to test the relationship between gender and the number of people living on less than two dollars a day. The independent variables used to measure gender are female population in thousands of people, the percentage of households that are managed by women, and the gender inequality index.

The results for specification 8 support the initial hypotheses. However, only the Gender Inequality Index proved to be statistically significant. The Gender Inequality Index is measured from one to zero. Nations that are closer to one have greater gender disparities while countries closer to zero experience almost no gender disparities. This is consistent with the results displayed in the first column of table 4 because a $10 \%$ increase in the gender inequality index is associated with a $39.41 \%$ increase in the percentage of people living on less than two dollars a day. In other words, high levels of the Gender Inequality Index are closely tied to more people living on less than two dollars a day. Conversely, as the percentage of women head of households rises, the number of people living on less than two dollars a day declines. Hence, a $10 \%$ increase in the number of female headed households is associated with a $5.19 \%$ decrease in the percentage of people living on less than two dollars a day.

Table 5: Relationship between Education and People Living on Less than $\$ 2 /$ day $\left(Y_{1}\right)$

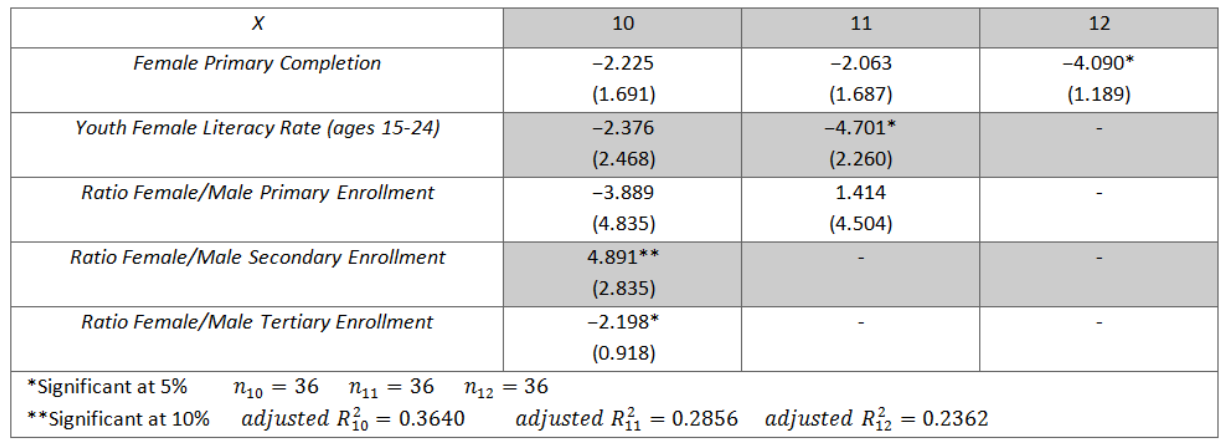


The independent variable for female population measured as natural logarithms of thousands of people has a positive relationship with the number of people living on less than two dollars a day. So, a $10 \%$ increase in the female population is associated with a $0.78 \%$ increase in the percentage of people living on less than two dollars a day. In order to retest the significance of the variable for female population, a specification with female population was run as the only independent variable. It was found that by adding more degrees of freedom, the coefficient increased, but it remained statistically insignificant. Explicitly, a 10\% increase in the female population is associated with a $2.08 \%$ increase in the percentage of people living on less than two dollars a day.

Table 5 lists the results of the last regression that was conducted in order to find the relationship between a selection of education variables and poverty measured by the number of people living on less than two dollars a day. For the purpose of this linear regression, education is measured by the female primary school completion rate, youth female literacy rate, ratio of female to male primary enrollment, ratio of female to male secondary enrollment, and ratio of female to male tertiary enrollment.

The hypotheses for specifications 10 through 12 are that the higher ratios of female to male enrollment, rates of youth female literacy, and female primary completion would be related to less people living on less than two dollars a day. Specification 10 shows that the data support this hypothesis except for the ratio of female to male secondary enrollment. It is worth mentioning that the youth female literacy rate and the ratio of female to male primary enrollment are not statistically significant for specification 10. The youth female literacy rate accounts for the women and girls ages 15 to 24 that can read and write as a percentage of the total population of women and girls ages 15 to 24. Specification 11 provides a statistically significant coefficient for the youth female literacy rate. A $10 \%$ increase in the youth female literacy rate amongst women and girls 15 to 24 years of age is associated with a $47.01 \%$ decrease in the percentage of people living on less than two dollars a day. The results shown are actually higher than the not statistically significant results of specification 10 , which state that a $10 \%$ increase in the youth female literacy rate amongst women and girls 15 to 24 years of age is associated with a $23.76 \%$ decrease in the percentage of people living on less than two dollars a day.

The female primary school completion rate measures the number of females in the final stage of primary education as a percentage of the females that should be in the last grade according to the entrance 
age. As can be seen in Table 5, this variable is inversely related to the number of people living on less than two dollars a day. Specification 10 shows that a $10 \%$ increase in the percentage of female primary completion is associated with a $22.25 \%$ decrease in the percentage of people living on less than two dollars a day. Specification 11 suggests that a $10 \%$ increase in the percentage of female primary completion is associated with a $20.63 \%$ decrease in the percentage of people living on less than two dollars a day. However, the estimated coefficients are not statistically significant. For this reason, one additional specification was run with the female primary completion rate as the only independent variable. Results indicated that a $10 \%$ increase in the percentage of female primary completion is associated with a $40.90 \%$ decrease in the percentage of people living on less than two dollars a day at a $95 \%$ level of confidence.

The relationship between the ratio of female to male primary enrollment and the number of people living on less than two dollars a day is inconclusive. In specification 10, the data show that a $10 \%$ increase in the percentage of girls to boys enrolled at a primary level is associated with a $38.89 \%$ decrease in the percentage of people living on less than two dollars a day. Specification 11 suggests that a $10 \%$ increase in the percentage of girls to boys enrolled at a primary level is associated with a $14.14 \%$ increase in the percentage of people living on less than two dollars a day. Although the result from specification 10 confirms the hypothesis and has a higher t-statistic, these estimated coefficients are not statistically significant. Contrary to the preliminary hypothesis, the percentage of girls to boys that enroll in secondary programs is positively related to poverty (as measured in this study). So, a $10 \%$ increase in the percentage of girls to boys enrolled at a secondary level is associated with a $48.91 \%$ increase in the percentage of people living on less than two dollars a day. Keeping in mind that these results are statistically significant, it is possible that more girls enroll but fail to complete the program, or that the cost of secondary education is high and the girls cannot escape poverty until they complete the program and find a job. Finally, the results shown in specification 10 for female to male enrollment in tertiary education is statistically significant and supports the first assumption by revealing that a $10 \%$ increase in the percentage of girls to boys enrolled at a tertiary level is associated with a $21.98 \%$ decrease in the percentage of people living on less than two dollars a day. 
Table 6: Relationship between Maternal Health and Gross Domestic Product per Capita $\left(Y_{2}\right)$

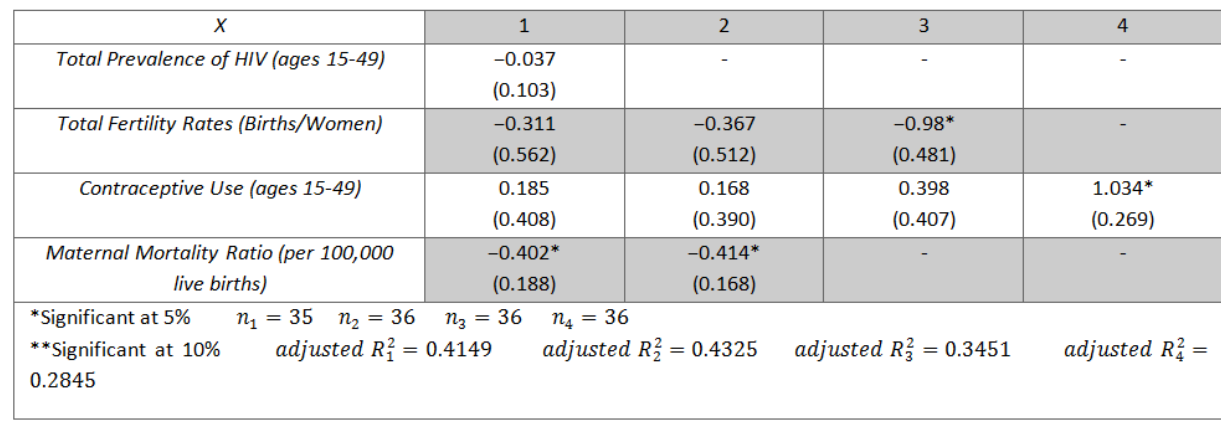

The next five tables display the results from the second regression equation. These tables depict the correlation of maternal health, social development, poverty, gender and education to economic development measured by using Gross Domestic Product per Capita.

Specification 1 in table 6 shows that the estimated coefficient of the maternal mortality rate was the only statistically significant independent variable although the coefficients support the preliminary hypotheses. The interpretation of elasticity indicates that a $10 \%$ increase in the maternal mortality rate is associated with a $4.02 \%$ decrease in the gross domestic product per capita. Similarly, a $10 \%$ increase in total prevalence of HIV for people between the ages of 15 and 49 is associated with a $0.37 \%$ decrease in the gross domestic product per capita. Therefore, the more people living with HIV in a country, the lower the level of economic development in that country. Furthermore, a 10\% increase in total fertility rates is associated with a $3.11 \%$ decrease in the gross domestic product per capita. Put simply, fewer births per women indicates higher levels of economic development. Conversely, a 10\% increase in the use of contraceptive methods in people between the ages of 15 and 49 is associated with a $1.85 \%$ increase in the gross domestic product per capita. This is consistent with the findings of Do \& Kurimoto (2012), who have shown that societies that have a higher use of contraceptive methods have higher levels of women's empowerment and are more likely to be more economically developed.

In an attempt to further test the variables for statistical validity, specification 2 was run without the variable for total prevalence of HIV. The results were quite similar to the first specification in that only the maternal mortality rate proved to be statistically significant. The findings in specification 2 show that a $10 \%$ increase in the maternal mortality rate is associated with a $4.14 \%$ decrease in the gross domestic product per capita. In addition, a $10 \%$ increase in the fertility rate is associated with a $3.67 \%$ decrease in the gross domestic product per capita. Conversely, 
a $10 \%$ increase in the use of contraceptive methods in people between the ages of 15 and 49 is associated with a $1.68 \%$ increase in the gross domestic product per capita.

A third specification showed that the estimated coefficient for totality fertility rates is statistically significant if analyzed solely alongside the variable for the use of contraceptive methods. The elasticity coefficient shows that a $10 \%$ increase in total fertility rates is associated with a $9.8 \%$ decrease in the gross domestic product per capita. Furthermore, a $10 \%$ increase in the use of contraceptive methods in people between the ages of 15 and 49 is associated with a $3.98 \%$ increase in the gross domestic product per capita. A final specification which allowed more degrees of freedom indicates that a $10 \%$ increase in the use of contraceptive methods in people between the ages of 15 and 49 is associated with $10.34 \%$ increase in the gross domestic product per capita with a $95 \%$ level of confidence.

Table 7: Relationship between Social Development and Gross Domestic Product per Capita $\left(Y_{2}\right)$

\begin{tabular}{|c|c|c|}
\hline$x$ & 5 & 6 \\
\hline GINI Index & $\begin{array}{l}-0.096 \\
(0.456)\end{array}$ & $\begin{array}{l}-0.250 \\
(0.438)\end{array}$ \\
\hline Inequality-adjusted HDI 2011 & $\begin{array}{l}-0.139 \\
(0.816)\end{array}$ & - \\
\hline Human Development Index & $\begin{array}{l}3.865^{*} \\
(1.034)\end{array}$ & $\begin{array}{l}3.403^{*} \\
(0.411)\end{array}$ \\
\hline $\begin{array}{lll}{ }^{*} \text { Significant at } 5 \% & n_{5}=34 \quad n_{6}=36 \\
{ }^{* *} \text { Significant at } 10 \% & \text { adjusted } R_{5}^{2}=0.7352\end{array}$ & adjusted $R_{6}^{2}=0.6601$ & \\
\hline
\end{tabular}

Table 7 explores the relationship between social and economic development. Social development, in this case, is measured by the GINI index, the human development index, and the inequality-adjusted human development index.

For both specifications, the only coefficient that is statistically significant is the human development index. Specification 5 indicates that a $10 \%$ increase in the human development index is associated with a

Inquipy 2016/2 $38.55 \%$ increase in the gross domestic product per capita. In addition, specification 6 shows that a $10 \%$ increase in human development index ${ }^{2}$ is associated with a $34.03 \%$ increase in the gross domestic product per capita. It is evident that in both cases, countries that experience higher levels of human development also have higher levels of economic development.

Specification 5 suggests that a 10\% increase in GINI index is asso-

2 It is worth mentioning that the Gross National Income is included in the measurement of the human development index which can raise some issues on the estimation. 
ciated with a $0.96 \%$ decrease in the gross domestic product per capita. Moreover, a 10\% increase in inequality-adjusted human development index is associated with a $1.39 \%$ decrease in the gross domestic product per capita. Specification 6 indicates that a $10 \%$ increase in the GINI index is associated with a $2.5 \%$ decrease in the gross domestic product per capita. Even though a second specification confirms the results and they all support the preliminary hypotheses, the estimated coefficients are not statistically significant.

The results listed in Table 8, explain the relationship between the independent variables used to measure poverty and the gross domestic product per capita. Poverty is measured by the poverty gap at $\$ 1.25$ a day, the multidimensional poverty index, and the number of people living on less than two dollars a day.

Initially, it was assumed that all these variables would decrease as the gross domestic product per capita increased, and vice versa. Estimation results in Table 8 support the preliminary hypothesis of a negative relationship between per capita GDP and each of the three measures of poverty. In particular, a $10 \%$ increase in the percentage of people living on less than $\$ 2$ a day is associated with a $4.05 \%$ decrease in the gross domestic product per capita. Although the other coefficients in specification 7 are not statistically significant, they show that a $10 \%$ increase in the poverty gap is associated with a $0.83 \%$ decrease in the gross domestic product per capita. Furthermore, a 10\% increase in the multidimensional poverty index is associated with a $0.53 \%$ decrease in the gross domestic product per capita.

Table 8: Relationship between Poverty and Gross Domestic Product per Capita $\left(Y_{2}\right)$

\begin{tabular}{|c|c|c|c|}
\hline$x$ & 7 & 8 & 9 \\
\hline Poverty Gap at $\$ 1.25 /$ day PPP $\%$ & $\begin{array}{l}-0.083 \\
(0.010)\end{array}$ & - & $\begin{array}{c}-0.189^{*} \\
(0.090)\end{array}$ \\
\hline Multidimensional Poverty Index 2013 & $\begin{array}{l}-0.053 \\
(0.133)\end{array}$ & $\begin{array}{c}-0.186^{* *} \\
(0.104)\end{array}$ & - \\
\hline People Living on Less than $\$ 2$ a day & $\begin{array}{c}-0.405^{*} \\
(0.076)\end{array}$ & - & - \\
\hline
\end{tabular}

In an attempt to test the significance of the multidimensional poverty index, the other variables that measure poverty were excluded and more observations in this specific sample were included. Specification 8 shows that a $10 \%$ increase in the multidimensional poverty index is associated with a $1.86 \%$ decrease in the gross domestic product per capita with a $90 \%$ level of confidence. Finally, specification 9 assesses the validity of the relationship between the poverty gap at $\$ 1.25$ a day and the gross domestic product per capita. The analysis shows that a 
$10 \%$ increase in the poverty gap is associated with a $1.89 \%$ decrease in the gross domestic product per capita.

Table 9 describes the correlation between gender and development. It is divided into two specifications and explains the coefficients for the variables of female population, female headed households, and the gender inequality index.

Table 9: Relationship between Gender and Gross Domestic Product per Capita $\left(Y_{2}\right)$

\begin{tabular}{|c|c|c|}
\hline$x$ & 10 & 11 \\
\hline Female Population (Thousands) & -0.026 & -0.086 \\
& $(0.095)$ & - \\
\hline Female Headed Households & -0.725 & - \\
\hline & $(0.310)$ & $-2.244^{*}$ \\
\hline Gender Inequality Index 2012 & $(0.547)$ & \\
\hline *Significant at 5\% & $n_{10}=28 \quad n_{11}=36$ & adjusted $R_{11}^{2}=-0.0053$ \\
\end{tabular}

Two specifications were conducted to test the statistical significance of the coefficients but the gender inequality index is the only variable that yielded a statistically significant coefficient. Hence, a $10 \%$ increase in the gender inequality index is associated with a $22.44 \%$ decrease in the gross domestic product per capita with a 95\% level of confidence. This confirms the initial hypothesis of a negative relationship between the gender inequality index and the gross domestic product per capita.

At the same time, the coefficient for female headed households discredits expectations by showing that a $10 \%$ increase in the number of female headed households is associated with a $7.25 \%$ decrease in the gross domestic product per capita. However, this coefficient is not statistically significant. It could be possible that this is not the best variable to measure women's empowerment, or that the limited sample size does not provide an accurate depiction of the real relationship. Both specifications 10 and 11 support the hypothesis by revealing that a $10 \%$ increase in the female population is associated with a $0.26 \%$ decrease in the gross domestic product per capita. In addition, a $10 \%$ increase in the female population is associated with a $0.86 \%$ decrease in the gross domestic product per capita. Nevertheless, neither of these coefficients is statistically significant. 
Table 10: Relationship between Education and Gross Domestic Product per Capita $\left(Y_{2}\right)$

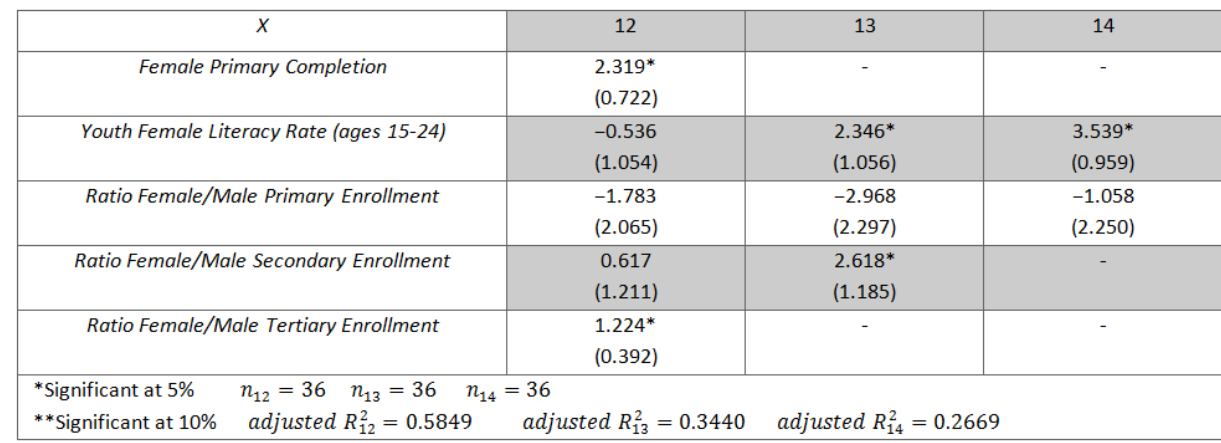

Finally, Table 10 explores the relationship between education and the gross domestic product per capita. Female education is measured by using the female primary completion rate, the youth female literacy rate, and the ratio of female to male primary/secondary/tertiary enrollment.

The results displayed in table 10 support the hypotheses except for the relationship between female to male primary enrollment and gross domestic product per capita which was expected to be positive. Specification 12 indicates that $10 \%$ increase in the ratio of girls to boys enrolled at a primary level is associated with a $17.83 \%$ decrease in the gross domestic product per capita. Specification 13 indicates that a 10\% increase in the percentage of girls to boys enrolled at a primary level is associated with a $29.68 \%$ decrease in the gross domestic product per capita. Specification 14 shows that a $10 \%$ increase in the percentage of girls to boys enrolled at a primary level is associated with a $10.58 \%$ decrease in the gross domestic product per capita. Although all three specifications uphold the negative relationship between the ratio of female to male primary enrollment and the gross domestic product per capita, the estimated coefficients are not statistically significant and more data may be needed to obtain a significant result.

Specification 12 shows that a $10 \%$ increase in the percentage of female primary school completion is associated with a $23.19 \%$ increase in the gross domestic product per capita and that a $10 \%$ increase in the percentage of girls to boys enrolled at a tertiary level is associated with a $12.24 \%$ increase in the gross domestic product per capita. Both of these coefficients are statistically significant. Moreover, this specification indicates that a $10 \%$ increase in the youth female literacy rate amongst women and girls 15 to 24 years of age is associated with a $5.36 \%$ decrease in the gross domestic product per capita and that a $10 \%$ increase in the percentage of girls to boys enrolled at a secondary level 
is associated with a $6.17 \%$ decrease in the gross domestic product per capita. Nevertheless, these estimated coefficients are not statistically significant.

Moreover, specification 13 suggests, that a $10 \%$ increase in the youth female literacy rate amongst women and girls 15 to 24 years of age is associated with a $23.46 \%$ increase in the gross domestic product per capita and that a $10 \%$ increase in the percentage of girls to boys enrolled at a secondary level is associated with a $26.18 \%$ increase in the gross domestic product per capita. The last specification confirms that a $10 \%$ increase in the youth female literacy rate amongst women and girls 15 to 24 years of age is associated with a $35.39 \%$ increase in the gross domestic product per capita, with a $95 \%$ level of confidence.

\section{CONCLUSION}

For the most part, the data support many of the preliminary hypotheses so in general it can be concluded that there is a significant relationship between empowerment of women, poverty reduction, and development. Therefore, this study may be useful to policy makers, specifically for those that work in any of the 36 sample countries, to assist them in understanding the types of programs that may be more effective. It is clear that programs focused on maternal health are more likely to reduce poverty, which would suggest greater investment in health infrastructure and the expansion of programs that educate women about pregnancy, sexual health, and sexually transmitted infections. The results also suggest that programs focused on women's education are more prone to foster development. Based on this, policymakers at local and national level should create incentives for women to further their education and implement programs that bring awareness to girls and women about gender disparities, while also improving their self-confidence and technical skills.

It is important to note here that the scope of this study is limited $2016 / 2$ and the findings may not be applicable to all developing countries. This suggests that the current data set could be expanded to include more developing countries and this may enable researchers to work with more degrees of freedom. In conclusion, this research does allow for a greater appreciation of women's standing in terms of education, health, development, gender, and poverty. 


\section{REFERENCES}

Ahmed, S., Creanga, A. A., Gillespie, D. G., \& Tsui, A. O. (2010). Economic Status, Education and Empowerment: Implications for Maternal Health Service Utilization in Developing Countries. PloS ONE, 5(6), 1-6.

Awan, M. S., Malik, N., Sarwar, H., \& Waqas, M. (2011). Impact of Education on Poverty Reduction. International Journal of Academic Research, 3(1), 660665.

Banerjee, A. V., \& Duflo, E. (2008). Mandated Empowerment. Annals of the New York Academy of Science, 1136, 333-341.

Booysne, A., Fourie, F. C., \& Botes, L. J. (2011). The development status of women in South Africa: Patterns and progress in the provinces. Development Southern Africa, 28(1), 99-119.

Campbell, M. L., \& Teghtsoonian, K. (2010). Aid Effectiveness and Women's Empowerment: Practices of Governance in the Funding of International Development. Signs: Journal of Women in Culture \& Society, 36(1), 177-201.

Do, M., \& Kurimoto, N. (2012). Women's Empowerment and Choice of Contraceptive Methodes in Selected African Countries. International Perspectives on Sexual and Reproductive Health, 38(1), 23-33.

Dorius, S. F., \& Firebaugh, G. (2010). Trends in Global Gender Inequality. Social Forces, 88(5), 1941-1968.

Ezeh, C., Anyiro, C., Ehiemere, I., \& Obioma, N. (2012). Gender Issues on Poverty Alleviation Programmes in Nigeria; the Case of the National Fadama 1 Development Project in Abia State,Nigeria. Agris On-Line Papers in Economics \& Informatics, 4(3), 15-20.

International Monetary Fund. (2013, August 5). Data and Statistics: World Economic Outlook Database, October 2010. Retrieved from The IMF Web site: http:// www.imf.org/external/ns/cs.aspx?id=28

Islam, M., Ali, R., Salehin, M., \& Islam, A. (2008). Rural Women and Poverty: A study on the role of RDRS for poverty alleviation in Bangladesh. Journal of Bangladesh Agricultural University, 6(2), 415-421.

Jayaweera, S. (1997). Women, Education and Empowerment in Asia. Gender and Education, 9(4), 411-423.

Joint United Nations Programme on HIV/AIDS. (2010). UNAIDS Report on the Global AIDS Epidemic 2010. UNAIDS Corporate.

Kadam, A. (2013). Women Empowerment: A Multidimensional Approach. Golden Research Thoughts, 2(7), 1-5.

Krishnan, S., Dunbar, M. S., Minnis, A. M., Medlin, C. A., Gerdts, C. E., \& Padian, N. S. (2008). Poverty, Gender Inequities, and Women's Risk of Human Immunodeficiency Virus/AIDS. Annals of the New York Academy of Sciences, $1136(1), 101-110$.

Malik, S. (2011). Higher Education and Women's Empowerment in Pakistan. Gender and Education, 23(1), 29-45.

Medel-Anonuevo, Carolyn, Ed. (1995). Women, Education and Empowerment: Path- 
ways towards Autonomy. UIE Studies 5, 25.

Murphy-Graham, E. (2008). Opening the black box: women's empowerment and innovative secondary education in Honduras. Gender and Education, 20(1), 3150 .

Mutongu, Z. B. (2012). Women's Participation in Community-Based Organizations' Development as a Strategy for Poverty Reduction in Kenya. Priscilla Papers, 26(1), 10-17.

Oxford Poverty and Human Development Initiative. (2007-2014). Global MPI: MPI 2013: MPI Data Bank. Retrieved from OPHDI Web site: http://www.ophi.org. uk/multidimensional-poverty-index/mpi-data-bank/

Salt, R. J. (2010). Exploring Women's Participation in a U.S. Microcredit Program. Journal of Nursing Scholarship, 42(3), 270-277.

Shetty, S. (2010). Microcredit, Poverty and Empowerment: Exploring the Connections. Perspective on Global Development and Technology, 9(3/4), 356-391.

Sindhe, J. (2013). Sustainable Women Empowerment throught Micro Finance in India. Global Research Thoughts, 2(12), 1.

The World Bank Group. (2014). Data. Retrieved from The World Bank Web Site: http://data.worldbank.org/

United Nations Development Programme. (2014). UNDP: Human Development Reports: Data. Retrieved from UNDP Web site: http://www.hdr.undp.org/en/data

Varghese, T. (2011). Women Empowerment in Oman: A study based on Women Empowerment Index. Far East Journal of Psychology and Business, 2(2), 37-49.

Yousefy, A., \& Baratali, M. (2011). Women, Employment and Higher education schoolings. Procedia: Social and Behavioral Sciences, 15, 3861-3869. 